\title{
Impacto do Mapeamento de threads na Degradação do Processador*
}

\author{
Thiarles Soares Medeiros $^{1}$, Arthur Francisco Lorenzon ${ }^{1}$ \\ ${ }^{1}$ Laboratório de Otimização de Sistemas - Universidade Federal do Pampa \\ Av. Tiaraju, 810 - CEP 97.546-550 - Alegrete - RS - Brazil \\ \{thiarlesmedeiros, aflorenzon\}@unipampa.edu.br
}

\section{Introdução}

Com o crescente número de unidades de processamento a dissipação de calor se tornou um problema significativo, acelerando o processo de envelhecimento dos componentes físicos, reduzindo a vida útil e tornando-os mais suscetíveis a diferentes tipos de falhas. Com o aumento da temperatura dos núcleos (core) ativos os núcleos próximos são afetados, aumentando a variação da temperatura. Portanto, o envelhecimento do processador não está relacionado apenas a quantas threads estão executando, mas também a como elas são distribuídas pelos núcleos disponíveis.

$\mathrm{Na}$ literatura, dois tipos de abordagens já foram propostas. Uma delas explorando o impacto do TLP, ajustando artificialmente o número de threads durante a execução e aplicando estratégias de afinidade/mapeamento (alocação de threads nos núcleos disponíveis) baseadas no desempenho e/ou energia, como apresentado em [Lorenzon and Beck Filho 2019] e [Lorenzon et al. 2019]. Outra abordagem explora a afinidade/mapeamento de threads apenas considerando o envelhecimento. Nenhuma delas avaliou a influência do TLP e da afinidade/mapeamento das threads no envelhecimento. Considerando o cenário mencionado, avaliamos o impacto de diferentes graus de exploração de TLP e estratégias de alocação de threads (afinidade e mapeamento) no envelhecimento dos componentes de hardware.

\section{Metodologia}

Treze aplicações já paralelizadas e escritas em $\mathrm{C} / \mathrm{C}++$ a partir de diversos benchmarks foram escolhidas. Elas foram classificadas de acordo com a quantidade de acessos à memória e uso da CPU: Memory-bound e CPU-Bound. Elas estão implementadas em OpenMP, na qual fornece variáveis de ambiente para controlar a afinidade e mapeamento das threads. As políticas de mapeamento de threads definem em quais CPUs as threads devem ser alocadas: threads, cores, e sockets. Dentro de cada política de mapeamento, as threads podem ser distribuídas pelos núcleos, seguindo cinco estratégias de afinidade distintas: false, true, master, close e spread.

Os experimentos foram realizadas em duas arquiteturas multicore, AMD e Intel. As seguintes configurações foram avaliadas: (i) AMD de 16 cores - cinco graus de TLP e não foi utilizada a política de mapeamento sockets; e, (ii) Intel de 32 cores - seis graus de TLP e todas políticas de mapeamento. A frequência da CPU foi configurada para ondemand como governor do DVFS, que é o padrão usado na maioria das versões do

\footnotetext{
*Este trabalho foi parcialmente financiado pela FAPERGS nos projetos 19/2551-0001224-1 e 19/25510001689-1, CNPq PIBIC e FAPERGS PROBIC.
} 
Linux. Compilamos as aplicações com o gcc/g++ 9.1, usando a opção de otimização -O3. Cada aplicação foi executada com o conjunto de entrada padrão.

No processador Intel, obtemos a temperatura da CPU a cada segundo diretamente do contador de hardware em tempo de execução. Quanto ao processador AMD a temperatura do núcleo é obtida por meio de simulação através dos valores de potência utilizada. Calculamos o processo de envelhecimento com base na temperatura operacional através da equação de Arrhenius, conforme definido em [Storino 2004].

\section{Resultados}

Por haver comunicação entre as threads nas aplicações MEM-Bound o número de threads e as estratégias de mapeamento e afinidade utilizadas durante a execução de uma aplicação desempenham um papel decisivo no envelhecimento do processador. Portanto, os melhores resultados foram alcançados na execução com um número de threads menor que o máximo disponível combinado às estratégias que (i) facilitam a comunicação entre as threads, alocando-as próximas uma das outras; (ii) ou as que distribuem as threads entre os núcleos para não sobrecarregar os recursos compartilhados. Os resultados para Intel e AMD apresentaram configurações distintas para os melhores casos. Os piores resultados foram alcançados quando a afinidade de threads foi definida como master, isso porque as threads são alocadas no mesmo local da thread principal. Com a configuração certa é possível reduzir o envelhecimento do processador em até $38 \%$ comparado à execução padrão do OpenMP. Também foi possível observar casos em que duas estratégias de afinidade de threads forneceram envelhecimento semelhante para todo o processador, mas envelheceram cada núcleo em razões distintas. Isto ocorreu devido ao fato que uma estratégia alocou as threads em núcleos específicos enquanto a outra não, reduzindo a possibilidade de criar pontos de calor.

Diferentemente das aplicações MEM-Bound, o envelhecimento do processador nas aplicações CPU-Bound depende mais do número de threads simultâneas em execução que da política de afinidade e mapeamento de threads. Nos processadores Intel e AMD, quanto maior o número de threads, menor o envelhecimento do processador. Embora a maioria das configurações executadas com 32 threads no processador Intel tenha apresentado resultados semelhantes (diferença de 4\%), o menor envelhecimento do processador foi alcançado com o par Sockets-close. Ao comparar com a execução padrão de aplicações OpenMP, o envelhecimento do processador é $11 \%$ menor. O mesmo comportamento, mas a taxas distintas, pode ser observado no processador AMD de 16 núcleos.

\section{References}

Lorenzon, A. F. and Beck Filho, A. C. S. (2019). Parallel Computing Hits the Power Wall. SpringerBriefs in Computer Science. Springer International Publishing.

Lorenzon, A. F., de Oliveira, C. C., Souza, J. D., and Beck, A. C. S. (2019). Aurora: Seamless optimization of openmp applications. IEEE Transactions on Parallel and Distributed Systems, 30(5):1007-1021.

Storino, S. N. (2004). Method and apparatus for estimating remaining life of a product. US Patent 6,775,624. 